\title{
Use of IAEA Radiation Dose Criteria to Assess the Need for Internal Radiation Dosimetry in Nuclear Medicine Practices
}

\author{
${ }^{1}$ Abdus Sattar Mollah, ${ }^{1} \mathrm{~K}$. Rahman, and ${ }^{2} \mathrm{M}$ D Hossain \\ ${ }^{1}$ Department of Nuclear Science and Technology, Military Institute of Science and Technology, ${ }^{2}$ SUST, Sylhet \\ Correspondence Address : Dr. Abdus Sattar Mollah, Department of Nuclear Science and Technology, Military Institute of Science \\ and Technology, Mirpur, Dhaka-1216. Email: mollahas@gmail.com
}

\begin{abstract}
The IAEA Safety Guide RS-G-1.2 recommends that occupational radiation monitoring should be implemented whenever it is likely that committed effective doses from annual intakes of radionuclides would exceed $1 \mathrm{mSv}$. This study presents the analysis of IAEA methodology for the evaluation of the need for the implementation of an internal monitoring program; considering that it should be carried out whenever the potential internal exposure of incorporation leads to a value of annual committed effective dose equal or higher than $1 \mathrm{~m} \mathrm{~Sv}$. The IAEA criteria applied to commonly used radionuclides in nuclear medicine, taking into consideration usual manipulated unsealed radioactive sources and handling conditions. It is concluded that the handling of unsealed radioactive sources presents the risk of internal radiation exposure to the workers, requiring the implementation of an internal dosimetry program by the concerned Nuclear Medicine Institutes/Centers.

Keywords: internal dosimetry, radiation control, IAEA criteria, implementation.
\end{abstract}

\section{INTRODUCTION}

In recent years, world population (both occupationally exposed workers and members of the public) exposure to ionizing radiation due to medical activities has increased sharply. Among the occupationally exposed workers in these fields, those most affected by this increased exposure to ionizing radiation are nuclear medicine workers, who, in their daily activities, need to manipulate a wide variety of unsealed radioactive sources, including patients, both for diagnostic and therapeutic purposes, resulting in a significant risk of internal radiation exposure. Nuclear medicine practices involve the handling of a wide range of radionuclides for diagnostic and therapeutic purposes. Due to the unsealed nature of the radioactive sources in nuclear medicine, nuclear medicine activities carry the potential risk of both external and internal radiation hazards. The use of ionizing radiation in medical imaging has increased and led to the remarkable increase of collective effective dose to the population. In the period covered by the 2008 UNSCEAR Report, the annual collective effective dose to the world population due to diagnostic nuclear medicine examinations is estimated to be 202,000 man Sv (1). The trend in the annual collective effective dose from diagnostic nuclear medicine examinations over the last three UNSCEAR surveys is shown in Figure.1.

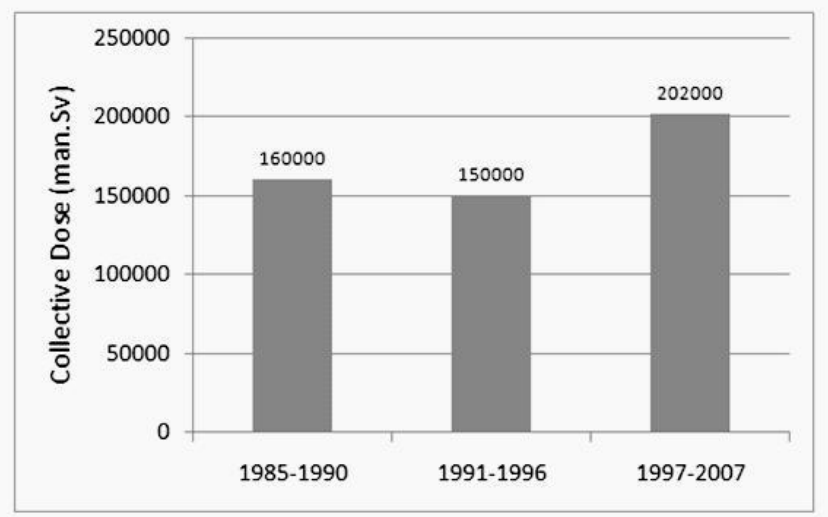

Figure 1.World-wise trend in the annual collective effective dose from diagnostic nuclear medicine examinations.

There has been an increase in collective dose of nearly 50,000 man $\mathrm{Sv}$, a rise of just over a third since the last report. According to the UNSCEAR report (1), the dose distribution of diagnostic imaging procedures is shown in Figure 2. From the Figure.2, it is evident that the nuclear 
medicine diagnostic imaging has a $7 \%$ contribution in the ionizing radiation population exposure.

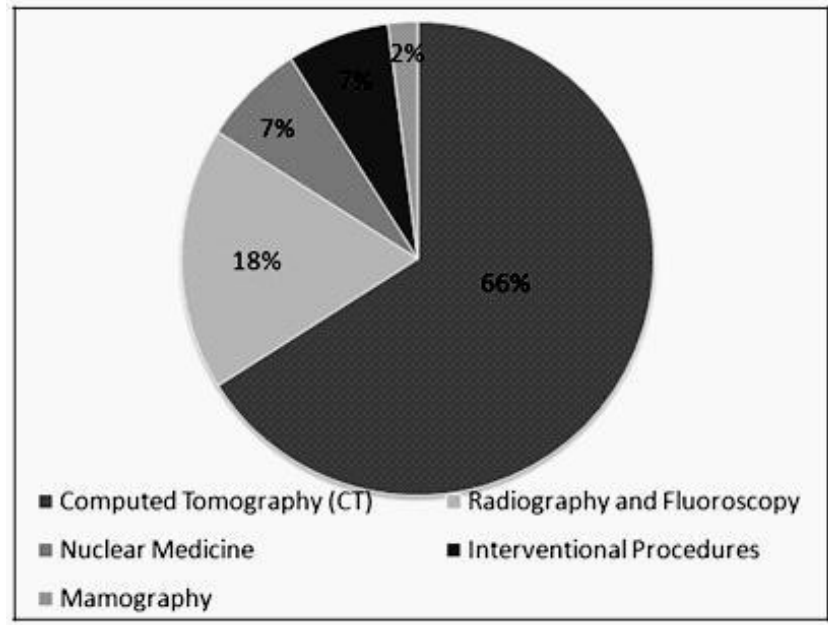

Figure 2. Piechart showing world-wise breakdown of radiation doses during diagnostic imaging procedures.

From a radiation protection perspective, an accurate assessment of the dose that nuclear medicine workers are subjected to must be performed not only for external radiation exposure, but also for internal radiation exposure. Moreover, according to the IAEA , the radiation control program should include an evaluation of such risks due to external and internal radiation exposure. In Bangladesh, the annual external radiation doses received by the staff of nuclear medicine departments for different nuclear medicine facilities were reported by Rahman et al. by TLD technique.

The collective dose due to external ionizing radiation from nuclear medicine practices in Bangladesh was estimated during 2013-14 and found to be $<80$ man.mSv.

From an internal dosimetry perspective, due to the nature of their activities, nuclear medicine workers are pointed out as being more at risk for internal contaminations. Some cases of internal contaminations have already been identified at nuclear medicine facilities. In Germany, Sweden and Hungary, the Euratom Council Directive 96/29 of 13 May 1996 concerning the radiation exposure monitoring was legally implemented and internal monitoring programs are mandatory. Besides ongoing developments in the dosimetry of incorporated radionuclides (mainly using the MIRD methodology), there have been various efforts to improve the monitoring of workers for potential or real intakes of radionuclides for internal dosimetry purpose. In 1999, the International Atomic Energy Agency (IAEA) published a safety guide, which aims at providing a set of criteria to be taken into account in order to determine the need, or not, for an internal monitoring program. Although this publication is not specific to nuclear medicine, recent studies and publications have applied these criteria to assess risk in nuclear medicine practices in some countries. The aim of this work is to describe an application of the mathematical criteria recommended by the IAEA to determine whether an internal dosimetry program is needed or not for radiation occupational works in nuclear medicine practices in Bangladesh.

\section{METHODS}

In order to evaluate the internal radiation risks involved in nuclear medicine practices in Bangladesh, a simplified mathematical relation is proposed based on the IAEA criteria IAEA. The criteria recommended by the IAEA to assess the need for internal dosimetry is based on the calculation of the decision factor (di), which takes into consideration safety factors related to the complexity of the task, handling conditions of the radioactive material, as well as the physical and chemical properties of the nuclide. IAEA criteria consider internal radiation dosimetry is necessary whenever the value of $\mathrm{dj}$ is above $1 \mathrm{~m} \mathrm{~Sv}$.

The specific radionuclide 'decision factor' di for a specific practice is calculated based on the IAEA formula with some additional correction factors as given in the following expression:

$\mathrm{d}_{j}=\frac{A_{j} \mathrm{e}(\mathrm{g}) j i n h}{\mathrm{f}_{(\mathrm{fs}) j} \mathrm{f}_{(\mathrm{hs}) j} \mathrm{f}_{(\mathrm{ps}) j}} \mathrm{xf}_{\text {workload }} \times \mathrm{x}_{\text {handled_activity }} \times \mathrm{x}_{\text {intakc }}(1)$ where, for each radionuclide $\mathrm{j}, \mathrm{Aj}$ is the average annual activity handled by the worker, $e(g)_{j i n h}$ is the dose coefficient for inhalation of 5-mm aerosols by workers (given in $\mathrm{Sv} / \mathrm{Bq}$ ), $\mathrm{f}_{(\mathrm{fs}) \mathrm{j}}$ is a physical form safety factor based on the physical and chemical properties of the handled material, $\mathrm{f}_{(\mathrm{hs}) \mathrm{j}}$ is a handling safety weighing factor, which accounts for the operations taken to handle 
radionuclide ' $\mathrm{j}$ ', $\mathrm{f}_{(\mathrm{ps}) \mathrm{j}}$ is a protection safety weighing factor, which accounts for the safety precautions taken while handling radionuclide ' $\mathrm{j}$ ' and 0.001 is a conversion factor from $\mathrm{Sv}$ to $\mathrm{mSv}, \mathrm{f}_{\text {workload }}$ is the fraction of time involved in a particular task by the worker in the scenario, $\mathrm{f}_{\text {hanled_activity }}$ is the fraction of handled activity by the worker in a scenario considering that in real practice each worker, according to his responsibilities, and $\mathrm{f}_{\text {intake }}$ is the fraction of the handled activity that could be incorporated by the worker through aerolization or volatization. In the majority of cases, ffs should be 0.01 , therefore equation 1 reduces to

$\mathrm{d}_{j}=10 A_{j} \mathrm{e}(\mathrm{g})_{j} \mathrm{f}_{(\mathrm{hs}) j} \mathrm{f}_{(\mathrm{ps}) j} \mathrm{x} \quad \mathrm{f}_{\text {workload }} \times \mathrm{f}_{\text {handled_activity }} \times \mathrm{f}_{\text {intakc }}(2)$

The final decision factor $\mathrm{D}$ for all radionuclides handled in the workplace is given by:

$$
\mathrm{D}=\sum_{j} d_{j}(3)
$$

According to the IAEA publication, the estimation of this decision factor should serve as a means to determine whether a given worker should be monitored for internal radiation incorporations (if $\mathrm{D}>1 \mathrm{mSv}$ ) or not (if $\mathrm{D}<1$ $\mathrm{mSv}$ ).Considering more than one radionuclide present in the workplace, monitoring of separated radionuclides decision is based on the following criteria:

1. all radionuclides with $\mathrm{di}>1$ should be monitored;

2. if $\mathrm{D}>1$, radionuclides with $\mathrm{di}>0.3$ should be monitored and monitoring of radionuclides with $\mathrm{di}<0.1$ is unnecessary.

It should be noted that this criterion applies to all types of practices involving some kind of risk for internal radiation exposure, and not only for nuclear medicine practices. This must be taken into account when assigning values to the weighing factors to be used for the estimation of the decision factor. The procedures implemented by nuclear medicine staff was analyzed based on the criteria defined in the IAEA guidelines to evaluate the need for internal radiation dosimetry. The dose coefficients used in the decision factor calculations derived from the bio-kinetic models of the International Commission on Radiological Protection-ICRP 68. All the parameters necessary to calculate dj are provided in the IAEA Safety Guide
RS-G-1.2. This methodology can also be used to calculate the maximum annual activity (Amax) for which an internal monitoring plan is recommended for a single radionuclide. This calculation is made by isolating the term $\mathrm{Aj}$ and attributing the value of $1 \mathrm{mSv}$ to the parameter dj by using the following expression:

$\mathrm{A}_{\max }=1 / 10 . \mathrm{e}(\mathrm{g})_{j \mathrm{jinh}} \cdot \mathrm{f}_{\mathrm{hs}} \cdot \mathrm{f}_{\mathrm{ps}} \times \mathrm{f}_{\text {workload }} \mathrm{x} \mathrm{f}_{\text {handled_activity }} \mathrm{x} \mathrm{f}_{\text {intake }}$

The values of the parameters fhs and fps used in this work for the calculation of $\mathrm{d}_{\mathrm{j}}$ and Amax were chosen in order to represent the radiation protection requirements for nuclear medicine facilities. The values of $\mathrm{e}(\mathrm{g}) \mathrm{jinh}$ used in the calculations of $\mathrm{d}_{\mathrm{j}}$ are based on bio-kinetic and dosimetric models released by the ICRP (2) and have been generated by the software RIDA (14). Based on the above mentioned information, the criteria analysis was performed by using excel program to assess the need for internal radiation dosimetry in nuclear medicine practices in Bangladesh.

\section{RESULTS AND DISCUSSION}

Table 1 presents the typical handled radionuclides as well as the dose coefficients for each radionuclide for inhalation of 5-mm activity median aerodynamic diameter aerosol by workers, chosen based on the chemical form in which it is used in nuclear medicine procedures. The values of annual activities of each radionuclide used in the calculations of dj presented in this work were obtained through a survey performed in all nuclear medicine centers in operation in Bangladesh during the year of 2006. Table 1 presents the results of the simulation for calculating the maximum activities ( $A_{\max }$ ) of each radionuclide of interest from which it is recommended to carry out a routine control of internal exposure of the staff through the implementation of an internal monitoring plan. It can be observed that the $\mathrm{dj}_{\mathrm{j}}$ corresponding to the maximum activities of all common radionuclides are still above $1 \mathrm{~m} \mathrm{~Sv}$. The handled activity in a year by the worker that could lead to an internal exposure above $1 \mathrm{~m}$ $\mathrm{Sv}$ according to the proposed modified formula results as shown in Table 1. This means, for example that $5.41 \mathrm{Ci}$ is the handled activity in a year by a worker that would lead to an internal exposure above $1 \mathrm{~m} \mathrm{~Sv}$. It may be excessive, since a 
nuclear medicine service could manipulate iodine-131 in the order of $200 \mathrm{mCi}$ or more per week. Considering the proposed scenario, internal radiation monitoring program should be included in the radiological protection plan, especially when used in therapeutic applications where the quantity of activity administered to each patient is usually several tens of milli-Curies.

Table 1. Amax according for selected radionuclides handled routinely in nuclear medicine practices with activity related to a $\mathrm{d}_{\mathrm{j}}=1 \mathrm{mSv}$.

\begin{tabular}{|l|c|c|c|}
\hline $\begin{array}{l}\text { Administered activity } \\
\text { of Radionuclide }(\mathrm{mCi})\end{array}$ & $\mathrm{e}(\mathrm{g})_{\text {inh }}(\mathrm{Sv} / \mathrm{Bq})$ & $\mathrm{A}_{\max }(\mathrm{Bq})$ & $\mathrm{A}_{\max }(\mathrm{mCi})$ \\
\hline${ }^{18} \mathrm{~F}(10)$ & $8.9 \times 10^{-11}$ & $4.49 \mathrm{E}+13$ & $1.21 \mathrm{E}+6$ \\
\hline${ }^{67} \mathrm{Ga}(5)$ & $2.8 \times 10^{-10}$ & $1.43 \mathrm{E}+13$ & $3.86 \mathrm{E}+5$ \\
\hline${ }^{99 m} \mathrm{Tc}(20)$ & $2.03 \times 10^{-11}$ & $1.97 \mathrm{E}+14$ & $5.33 \mathrm{E}+6$ \\
\hline${ }^{111} \mathrm{In}(0.5)$ & $3.1 \times 10^{-10}$ & $1.29 \mathrm{E}+13$ & $3.49 \mathrm{E}+5$ \\
\hline${ }^{123} \mathrm{I}(10)$ & $2.13 \times 10^{-10}$ & $1.88 \mathrm{E}+13$ & $5.08 \mathrm{E}+5$ \\
\hline${ }^{131} \mathrm{I}(0.03)$ & $1.1 \times 10^{-8}$ & $2.00 \mathrm{E}+11$ & $5.41 \mathrm{E}+3$ \\
\hline${ }^{201} \mathrm{Tl}(2)$ & $7.80 \times 10^{-11}$ & $5.13 \mathrm{E}+12$ & $1.39 \mathrm{E}+5$ \\
\hline
\end{tabular}

This work presents an application example including only one radionuclide, but in real scenarios, the same worker may be assigned multiple duties involving the handling of other radionuclides. The decision whether such workers require individual monitoring should be based on a careful review of all workers' duties and mainly the different radiation conditions in each scenario. Direct application of the criteria suggested in the IAEA Safety Guide (15) would likely require internal monitoring for most of the workers in the field of nuclear medicine, representing a high cost on this practice. Even if less restrictive parameters suggested in the IAEA safety guide were adopted in the calculation of $\mathrm{dj}$, it is likely that internal monitoring would be required. For example, it would be necessary to implement internal monitoring plans in all facilities where the annual quantity of 131-I activity handled exceeded 5.41 Ci (200 GBq). These studies should include a comprehensive national survey of worker exposures determined by in vivo and in vitro bioassay as well as aerosol sampling in nuclear medicine laboratories to provide actual data to evaluate risks associated with the practice of nuclear medicine. Almost all workers perform more than one operation, which means that the estimated $\mathrm{d}$ values obtained must be summed for each worker in order to obtain the final decision factor D. Then, summing the $\mathrm{d}$ values for each worker in order to obtain the final $\mathrm{D}$ and the occupational radiation workers should be integrated in a routine monitoring program for internal radiation exposure $(\mathrm{D}>1 \mathrm{mSv})$. This study suggests that a routine monitoring program for internal exposures should be implemented in Bangladesh for most nuclear medicine workers. Radiation workers potentially can receive radiation doses in two distinct ways: external exposure and internal intake. The total effective dose equivalent (TEDE) concept makes it possible to combine these dose components in assessing the overall risk to the health of an individual. The TEDE is equal to the sum of the deepdose equivalent (DDE), resulting from external exposures, and the committed effective dose equivalent (CEDE), resulting from internal exposures.

\section{CONCLUSION}

This study presents the analysis of IAEA methodology for the evaluation of the need for the implementation of an internal monitoring program; considering that it should be carried out whenever the potential internal exposure of incorporation leads to a value of annual committed effective dose equal or higher than $1 \mathrm{mSv}$. This work suggests that, according to the IAEA criteria, a routine monitoring program for internal exposures should be implemented for nuclear medicine workers. It should be noted, however, that the IAEA guide does not specifically mention the periodicity of the monitoring to be implemented. However, long-lived isotopes, especially the ones that can be fixed by specific critical organs are clearly more significant. Isotopes such as 131-I (half-life 8days), which is a thyroid seeker can imply a much more demanding procedure if a periodic monitoring is to be established. However, the specificities of the different measuring techniques available for internal monitoring may also play an important role in the monitoring program optimization. All these aspects should be taken into account when implementing a routine monitoring program. As a consequence, depending on the radionuclides handled as well as their in vivo behavior, if the IAEA criteria were to be taken into account, these workers should be monitored by in vivo methods, such as whole-body counters or in vitro techniques, such as biological 
samples such as urine and feces (9). The licensee of nuclear medicine facility, to the extent practical, must achieve occupational doses that are not only within regulatory limits but also ALARA principle.

\section{Licensees must either:}

- Monitor external and/or internal occupational radiation exposure; or

- Demonstrate that an unmonitored individual is not likely to receive a radiation dose $>10 \%$ of the occupational dose limits.

\section{REFERENCES}

1. UNSCEAR (United Nations Scientific Committee on the Effects of Atomic Energy). Report on sources and effects of ionizing radiation. Annex A: medical radiation exposures (2008).

2. IAEA Safety Standards:Radiation Protection and Safety of Radiation Sources-International Basic Safety Standards, No. GSR Part 3, 2014.

3. M. S. Rahman, A. Begum, A. Hoque, R. Karim Khan and Miah M. M.Siraz. Assessment of whole-body occupational radiation exposures in nuclear medicine practices of Bangladesh during 2010-2014, Iran J Nucl Med 2016:24; 51-58(1),

4. ICRP Publication 105. Radiation protection in medicine. Ann ICRP. 37, 1-63, 2007.

5. M. Salvatori, and G. Luchignani, Radiation exposure, protection and risk from nuclear medicine procedures. Eur. J. Nucl. Med. Mol. Imaging 2010:37;1225-1234.

6. S. Baechler, N.Stitt, andF. O. Bochud. Individual monitoring of internal exposure for nuclear medicine workersin Switzerland. Radiat Prot Dosim 2010;doi:10.1093/rpd/ncq350,

7. Kerekes, A., Kicsy, G. and Pellet, S. Individual monitoring for internal exposure of workers: regulation and practice in Hungary. Radiat Prot Dosim 2007;125(1-4):33-36.

8. R. Corbo. Evaluation of internal exposure of nuclear medicine staff through in vivo and in vitro bioassay techniques. Rad Prot Dosimy 2007;127: 465-468,.
9. M.J. Ferdous, Z.Alam, R.K. Khan, S.M. Iqubal, A. Islam, M.A.Rahman and AleyaBegum, Bangladesh Journal of Medical Physics 2012:5(1):63-69,.

10. European Communities. 96/29/EURATOM Directive, 13th May 1996. Laying down basic safety standards for the protection of the health of workers and the general public against the dangers arising from ionizing radiation, 1996.

11. Michael Stabin. Nuclear medicine dosimetry. Phys Med Biol 2006;51:R187-R202.

12. Bertelli1, L.; Melo, D. R.; Lipsztein, J.; Cruz-Suarez, R., AIDE: Internal dosimetry software, Radia Prot Dosim 2008:1-10.

13. S. M. Iqubal, A. S. Mollah, and A. H. M. R. Quddus. Internal dosimetry software for dose assessment due to inhalation of 131I radionuclide by occupational workers, Bangladesh J. Nucl.Med 2011;14;33-38.

14. A.S. Mollah, S. M. Iqubal and A.H.M. R. Quddus, RIDA-A software package for internal radioactivity and radiation dose assessment in nuclear medicine practices, Bangladesh J Nucl Med 2011;14:63-67.

15. International Atomic Energy Agency (IAEA). Assessment of occupational exposure due to intake of radionuclides. Safety Guide 1999:No.RS-G-1.2.

16. Dantas, B. M., Lucena, E. A. and Dantas, A. L. A. Internal exposure in nuclear medicine: application of IAEA criteria to determine the need for internal monitoring. Braz Arch Biol Tech 2008;51; 103-107.

17. J. Bento, P. Teles, M. Neves, A. I. Santos, G. Cardoso, A. Barreto, F. Alves, C. Guerreiro, A. Rodrigues, J. A. M. Santos, C. Capelo, R. Parafita and B. Martins, Study of nuclear medicine practices in Portugal from an internal dosimetry perspective, Radiation Protection Dosimetry 2011;149(4):438-43.

18. A. S. Mollah et al.,. "Report on Regulatory Survey/Inspection of Nuclear Medicine Practices in Bangladesh"'2006:3/78.

19. K. Rahman, A study on the radiation protection aspects in the Sylhet Nuclear Medicine Center, M.Sc. Thesis, SUST, Sylhet, 1999.

20. International Commission on Radiological Protection. Dosecoefficients for intakes of radionuclides by workers.Publication No. 68, Elsevier Science, Oxford, 1994.

21. M. S.Rahman, A. S. Mollah, A. Begum, M. Islam and M. A. Zaman, Body radioactivity and radiation dose from $40 \mathrm{~K}$ in Bangladesh subjects measured with a whole-body counter, Radiation Protection Dosimetry, 2008;130;236-239. 